\title{
ULOGA ODRŽIVE STOPE RASTA U UPRAVLJANJU KORPORATIVNIM FINANSIJAMA
}

\author{
Zoran Jovićl`, Kosana Vićentijević ${ }^{1}$, Milenko Stanić ${ }^{2}$ \\ ${ }^{1}$ Univerzitet Singidunum, Danijelova 32, Beograd, Srbija \\ ${ }^{2}$ Univerzitet Sinergija, Raje Baničića bb, Bijeljina, Republika Srpska
}

\begin{abstract}
Apstrakt:
Sve profitabilne korporacije mogu zapasti u finansijske poteškoće, pa čak i bankrotstvo, ukoliko rastu sporije ili brže nego što je to optimalno. Ocena presporog ili prebrzog rasta korporativnih preduzeća postiže se upoređivanjem sa njihovom održivom stopom rasta. Sama održiva stopa rasta predstavlja maksimalnu stopu rasta koju jedna korporacija može ostvariti bez dodatnog zaduživanja. Cilj ovog istraživanja jeste da se utvrdi održiva stopa rasta pojedinih korporativnih preduzeća u Srbiji i Republici Srpskoj u 2012. i 2013. godini, kao i da li postoje razlike između tih korporacija u Srbiji i Republici Srpskoj po ovom pitanju. Pored toga, autori nastoje da utvrde i realnu održivu stopu rasta analiziranih preduzeća u Srbiji i Republici Srpskoj uzimanjem u obzir aktuelne stope inflacije u posmatranim godinama, kao i da objasne uzroke različitosti između nominalnih i realnih održivih stopa rasta. Utvrđene realne održive stope rasta analiziranih korporativnih preduzeća u pomenutim zemljama mogu poslužiti kao orijentir u donošenju zaključka o razvojnom potencijalu ovih korporacija i oslonac u pronalaženju adekvatnih internih i eksternih podsticaja koji su potrebni za dalji potencijalni rast ovih korporacija.
\end{abstract}

\author{
Ključne reči: \\ održiva stopa rasta, \\ korporacija, \\ finansijsko upravljanje, \\ dividendna politika.
}

\section{UVOD}

SGR - sustainable growth rate ili održiva stopa rasta jedne korporacije predstavlja maksimalnu stopu rasta koju ta korporacija može da ostvari bez dodatnog zaduživanja. U slučaju da određena korporacija raste po nižoj stopi od održive stope rasta, to je može voditi u stagnaciju i gubitak konkurentske pozicije, a u dužem vremenskom periodu može dovesti i do bankrotstva takve korporacije. U obrnutom slučaju, ukoliko jedna korporacija pak raste prebrzo, tj. ukoliko raste po stopi koja je viša od održive stope rasta, to je može voditi u finansijske probleme čiji je uzrok prezaduživanje, odakle dolazi do problema nelikvidnosti, što u krajnjem slučaju nakon dužeg vremenskog perioda, takođe može voditi korporaciju do bankrotstva. Ubrzani rast korporacija se može finansirati na interni i eksterni način. $\mathrm{Na}$ interni način, korporacije mogu povećavati efikasnost svog poslovanja, mogu ubrzavati obrt ukupne imovine i obrt svih pojedinačnih delova imovine, čime stvaraju osnov za rast sopstvene akumulacije. Na eksterni način, korporacije se mogu finansirati povećanjem zaduženosti kod banaka i drugih finansijskih institucija i emitovanjem sopstvenih dužničnih hartija od vrednosti ili dokapitalizacijom putem dodatne emisije akcija na finansijskom tržištu.

Prebrzi rast može da bude u suprotnosti sa finansijskom politikom korporacija (Higgins, 1997). Ukoliko povećanje prodaje ide preko održive stope rasta, to korporaciju uvodi u finansijske probleme, jer zahteva nova zaduživanja za finansiranje ubrzanog rasta. Povećanje prodaje korporacija može biti rezultat povećanog obima prodaje roba i usluga ili rezultat povećanja cena roba i usluga. Zbog toga je neophodno razmotriti i uticaj inflacije na održivu stopu rasta (Higgins, 1981). Važan zadatak vlasnika i menadžmenta korporacija je utvrđivanje održive stope rasta. Utvrđivanje $S G R$ je utvrđivanje najviše stope rasta koju korporacija može da održi bez povećanja svog finansijskog leveridža (Brealey \& Myers, 2003). Model održivog rasta predstavlja efikasno sredstvo za finansijsko planiranje i usmeravanje poslovne politike ka stimulaciji rasta u pojedinim privrednim granama (Clouse \& McFaddin, 1994). Utvrđivanjem odnosa između investicione odluke o optimalnom rastu i politike isplate dividendi proširen je Higinsov model održivog rasta modelom koji optimizuje održivu stopu rasta i racio isplate dividendi (Chen et al., 2013).

U istraživanju su korišćene osnovne naučne metode analize i sinteze, idukcije i dedukcije, metoda komparacije, statističke metode i hipotetičko-deduktivne metode. Za prikupljanje podataka korišćena je metoda analize sadržaja dokumenata.

U fokusu ovog istraživanja su profitabilne korporacije iz različitih privrednih grana iz Srbije i Republike Srpske, jer samo korporacije sa pozitivnim finansijskim rezultatom, tj. korporacije koje ostvaruju dobit, mogu ostvariti i određenu održivu stopu rasta. Analizirane su 4 korporacije iz Srbije čijim se akcijama trguje na Beogradskoj berzi, i to po jedna 
korporacija iz prerađivačkog sektora, građevinskog sektora, poljoprivrednog sektora i turističkog sektora. Takođe su uporedo analizirane 4 korporacije iz Republike Srpske čijim se akcijama trguje na Banjalučkoj berzi i to po jedna korporacija iz građevinskog sektora, sektora rudarstva i prerade, sektora poljoprivrede i šumarstva i turističkog sektora. Pažnja je usmerena na slične sektore u obe države, koji svojim prirodnim predispozicijama imaju značajan razvojni potencijal u ovim zemljama. Otuda i interesovanje autora istraživanja za analizu održive stope rasta posmatranih korporacija u Srbiji i Republici Srpskoj. U istraživanje su uključene korporacije iz Srbije i Republike Srpske, kako bi se sprovela komparativna analiza održivih stopa rasta odabranih korporacija u obe zemlje, a obuhvaćen je period analize za 2012. i 2013. godinu. Takođe, analiziran je odnos između održive stope rasta odabranih korporacija u obe zemlje i stope inflacije u posmatranim godinama sa ciljem da se utvrdi da li je $\mathrm{u}$ tom periodu postojao realni potencijal za rast analiziranih korporacija.

U istraživanju se polazi od sledećih predloženih hipoteza:

H1: Ne postoji značajna razlika između održive stope rasta korporacija u Srbiji i Republici Srpskoj.

$\mathrm{H} 2$ : Ne postoji značajna razlika između održive stope rasta korporacija u Srbiji i Republici Srpskoj u 2013. godini u odnosu na 2012. godinu.

H3: Ne postoji značajna razlika između nominalne i realne održive stope rasta korporacija u Srbiji i Republici Srpskoj u 2012. godini.

H4: Ne postoji značajna razlika između nominalne i realne održive stope rasta korporacija u Srbiji i Republici Srpskoj u 2013. godini.

\section{ODREĐIVANJE ODRŽIVE STOPE RASTA KORPORACIJA U SRBIJI I REPUBLICI SRPSKOJ}

\section{Za utvrđivanje održive stope rasta koristi se formula:}

$$
\mathrm{g}=\mathrm{b} \times \mathrm{ROE}
$$

pri čemu g označava održivu stopu rasata; b označava racio dobiti koji nije isplaćen kroz dividende, tzv. retention rate, odnosno deo dobiti koji ostaje u preduzeću za dalji razvoj; ROE - return on equity odnosno stopa prinosa na sopstveni kapital ili popularno: profitna stopa (Jović et al., 2015).

U postupku izračunavanja održive stope rasta, $R O E$ se primenom DuPont analize razlaže na sledeće komponente: profitnu maržu, racio obrta poslovne imovine i multiplikator sopstvenog kapitala (Stowe, 2000).

Prema prethodno utvrđenoj metodologiji izračunate su održive stope rasta (g) za po 4 uzorkovane korporacije iz Srbije i Republike Srpske u 2012. i 2013. godini, a rezultati su prikazani u tabelama 1, 2, 3 i 4 .

Iz tabela 1 i 2 može se uočiti da ne postoji značajna razlika između održive stope rasta korporacija u Srbiji u 2013. godini u odnosu na 2012. godinu, uz konstataciju da su tri korporacije zabeležile višu, a jedna nižu održivu stopu rasta u 2013. godini. Dividendna politika analiziranih korporacija iz Srbije u obe posmatrane godine je nepromenjena i ujednačena. Prerađivačka i građevinska korporacija su isplaćivale dividende $\mathrm{u}$ skoro neizmenjenom, stabilnom procentu, dok turističko-hotelska korporacija i poljoprivredna korporacija nisu isplaćivale dividende iz ostvarene dobiti, odnosno njihov retention rate je bio ravan jedinici, tj. svu ostvarenu dobit su reinvestirale. Neisplaćivanje dividendi iz ostvarene dobiti pozitivno utiče na visinu održive stope rasta, ali zbog relativno niskih profitnih stopa ovih korporacija (turističko-hotelska korporacija Palisad sa Zlatibora 2,29\% u 2012. godini i $0,19 \%$ u 2013. godini, a poljoprivredna korporacija PKB 1,39\% u 2012. godini i značajno više tj. 9,12\% u 2013. godini), krajnji rezultat koji se u uslovima kada je retention racio jednak 1 izjednačava sa profitnom stopom, je takođe skorman. Značajnu održivu stopu rasta u obe godine je imala samo prerađivačka korporacija Bambi iz Požarevca $(20,70 \%$ u 2012. godini i $26,95 \%$ u 2013. godini). Nižu, ali stabilnu održivu stopu rasta je imala građevinska korporacija Jedinstvo iz Sevojna (6,78\% u 2012. godini i 7,17\% u 2013. godini).

Da bi se odabrane korporacije iz Srbije uporedile sa korporacijama iz Republike Srpske u analizu su uključene 4 odabrane korporacije iz Republike Srpske takođe iz različitih sektora u 2012. i 2013. godini. Uočljivo je da ne postoji značajna razlika između održive stope rasta korporacija u Republici Srpskoj u 2013. godini u odnosu na 2012. godinu uz konstataciju da dve korporacije beleže višu, a jedna nižu održivu stopu rasta u 2013. godini. Dividendna politika analiziranih korporacija u Republici Srpskoj se razlikovala u 2012. i 2013. godini. U 2012. godini samo je rudarska korporacija Boksit iz Milića isplaćivala dividende u iznosu od $25 \%$ ostvarene dobiti, odnosno njen retention rate je iznosio 0,75 , dok ostale korporacije nisu isplaćivale dividende i celokupnu ostvarenu dobit su reinvestirale (retention rate 1,00). U 2013. godini, pored korporacije Boksit iz Milića sa retention rate 0,83 i turističko hotelska korporacija Banja Vrućica iz Teslića je isplatila dividende i to u iznosu od 55\% ostvarene dobiti, odnosno njen retention rate je iznosio 0,45 , što je uzrokovalo da se održiva stopa rasta ove korporacije u 2013. godini prepolovi u odnosu na prethodnu godinu, a i u odnosu na profitnu stopu. Upoređivanjem podataka može se uočiti da postoji značajna razlika u nivou održivih stopa rasta u ove dve zemlje, pri čemu su održive stope rasta (g) posmatranih korporacija u Srbiji na znatno višem nivou nego u Republici Srpskoj u obe analizirane godine $(20,70 ; 6,78 ; 2,29 ; 1,39$ vs. 2,$59 ; 1,68 ; 3,12 ; 0,03$ u 2012. godini i 26,$95 ; 7,17 ; 0,19 ; 9,12$ vs. 6,$13 ; 3,47 ; 1,46 ; 0,03$ u 2013 . godini).

Za utvrđivanje realnih razlika u visini održivih stopa rasta analiziranih korporacija u obe zemlje potrebno je u analizu uključiti i zvaničnu stopu inflacije u posmatranim godinama. U tabelama 5 i 6 je uključena i stopa inflacije u Srbiji koja je merena indeksom potrošačkih cena i koja je iznosila $12,2 \% \mathrm{u}$ 2012. godini i 2,2\% u 2013. godini (http://www.mfin.gov.rs/). Stopa inflacije u Srbiji je u 2012. godini imala visok nivo od $12,2 \%$, što je uticalo da samo jedna analizirana korporacija iz Srbije u toj godini zabeleži pozitivnu realnu održivu stopu rasta, tj. da je imala realni potencijal za rast od 8,50\% (Bambi, Požarevac). Ostale analizirane korporacije iz Srbije su ostvarile negativnu realnu održivu stopu rasta, jer je njihova ostvarena nominalna održiva stopa rasta bila niža od stope inflacije, pa te korporacije nisu imale realni potencijal za samostalni održivi rast u 2012. godini. Situacija je bila znatno drugačija u 2013. godini i to ne zbog mnogo bolje održive stope rasta posmatranih korporacija, već prvenstveno zbog niske stope inflacije u Srbiji od samo 2,2\%, što je uticalo da 3 analizirane korporacije ostvare pozitivnu realnu održivu stopu rasta, a samo jedna korporacija blagu negativnu održivu stopu rasta, što znači da je većina posmatranih korporacija imala realni potencijal za samostalni rast u 2013. godini. 
Tabela 1. Održive stope rasta izabranih preduzeća u Srbiji u 2012. godini

\begin{tabular}{|c|c|c|c|c|c|c|}
\hline Preduzeće & $\mathrm{b}$ & $\mathrm{ROE}$ & Profitna marža & $\begin{array}{l}\text { Racio obrta } \\
\text { ukupne imovine }\end{array}$ & $\begin{array}{l}\text { Multiplikator } \\
\text { sopstvenog } \\
\text { kapitala }\end{array}$ & $\mathrm{g}$ \\
\hline & $(1)$ & $(2)=\left(3^{\star} 4^{\star} 5\right)$ & (3) & $(4)$ & $(5)$ & $(6)=\left(1^{\star} 2\right)$ \\
\hline Bambi, Požarevac & 0,80 & 25,87 & 13,48 & 0,98 & 1,95 & 20,70 \\
\hline Jedinstvo, Sevojno & 0,61 & 11,12 & 5,88 & 0,97 & 1,95 & 6,78 \\
\hline Palisad, Zlatibor & 1,00 & 2,29 & 1,14 & 0,62 & 3,25 & 2,29 \\
\hline $\begin{array}{l}\text { PKB Korporacija, } \\
\text { Beograd }\end{array}$ & 1,00 & 1,39 & 6,28 & 0,14 & 1,62 & 1,39 \\
\hline
\end{tabular}

Izvor: Prikaz autora na osnovu podataka iz www.belex.rs

Tabela 2. Održive stope rasta izabranih preduzeća u Srbiji u 2013. godini

\begin{tabular}{|c|c|c|c|c|c|c|}
\hline Preduzeće & $\mathrm{b}$ & ROE & Profitna marža & $\begin{array}{c}\text { Racio obrta } \\
\text { ukupne imovine }\end{array}$ & $\begin{array}{c}\text { Multiplikator } \\
\text { sopstvenog } \\
\text { kapitala }\end{array}$ & g \\
\hline & $(1)$ & $(2)=\left(3^{\star} 4^{\star} 5\right)$ & (3) & $(4)$ & (5) & $(6)=\left(1^{\star} 2\right)$ \\
\hline Bambi, Požarevac & 0,80 & 33,69 & 18,86 & 1,10 & 1,63 & 26,95 \\
\hline Jedinstvo, Sevojno & 0,64 & 11,20 & 5,98 & 0,98 & 1,90 & 7,17 \\
\hline Palisad, Zlatibor & 1,00 & 0,19 & 0,12 & 0,30 & 5,25 & 0,19 \\
\hline $\begin{array}{l}\text { PKB Korporacija, } \\
\text { Beograd }\end{array}$ & 1,00 & 9,12 & 46,13 & 0,14 & 1,43 & 9,12 \\
\hline
\end{tabular}

Izvor: Prikaz autora na osnovu podataka iz www.belex.rs

Tabela 3. Održive stope rasta izabranih preduzeća u Republici Srpskoj u 2012. godini

\begin{tabular}{|c|c|c|c|c|c|c|}
\hline Preduzeće & $\mathrm{b}$ & ROE & Profitna marža & $\begin{array}{c}\text { Racio obrta } \\
\text { ukupne imovine }\end{array}$ & $\begin{array}{c}\text { Multiplikator } \\
\text { sopstvenog } \\
\text { kapitala }\end{array}$ & $\mathrm{g}$ \\
\hline & $(1)$ & $(2)=\left(3^{\star} 4^{\star} 5\right)$ & (3) & $(4)$ & $(5)$ & $(6)=\left(1^{\star} 2\right)$ \\
\hline Boksit, Milići & 0,75 & 3,46 & 1,61 & 0,62 & 3,46 & 2,59 \\
\hline Krajina GP B. Luka & 1,00 & 1,68 & 1,61 & 0,62 & 1,68 & 1,68 \\
\hline Banja Vrućica, Teslić & 1,00 & 3,12 & 8,98 & 0,26 & 1,32 & 3,12 \\
\hline $\begin{array}{l}\text { Industrijske plantaže } \\
\text { B. Luka }\end{array}$ & 1,00 & 0,03 & 1,67 & 0,02 & 1,01 & 0,03 \\
\hline
\end{tabular}

Izvor: Prikaz autora na osnovu podataka iz www.blberza.com

Tabela 4. Održive stope rasta izabranih preduzeća u Republici Srpskoj u 2013. godini

\begin{tabular}{lcccccc}
\hline \multicolumn{1}{c}{ Preduzeće } & $\mathrm{b}$ & ROE & Profitna marža & $\begin{array}{c}\text { Racio obrta } \\
\text { ukupne imovine }\end{array}$ & $\begin{array}{c}\text { Multiplikator } \\
\text { sopstvenog } \\
\text { kapitala }\end{array}$ \\
\cline { 2 - 7 } & $(1)$ & $(2)=\left(3^{\star} 4^{\star} 5\right)$ & $(3)$ & $(4)$ & $(5)$ & $(6)=\left(1^{\star} 2\right)$ \\
\hline Boksit, Milići & 0,83 & 7,39 & 3,10 & 0,72 & 3,31 & 1,55 \\
\hline Krajina GP B. Luka & 1,00 & 3,47 & 3,10 & 0,72 & 1,32 & 3,47 \\
\hline Banja Vrućica, Teslić & 0,45 & 3,24 & 8,98 & 0,27 & 1,01 & 0,03 \\
\hline $\begin{array}{l}\text { Industrijske plantaže } \\
\text { B. Luka }\end{array}$ & 1,00 & 0,03 & 2,74 & 0,01 & \\
\hline
\end{tabular}

Izvor: Prikaz autora na osnovu podataka iz www. blberza.com 
Tabela 5. Realne SGR odabranih preduzeća u Srbiji u 2012. godini

\begin{tabular}{lccc}
\hline \multicolumn{1}{c}{ Preduzeće } & g - održiva stopa rasta & stopa inflacije & realna održiva stopa rasta \\
\hline Bambi, Požarevac & 20,70 & 12,2 & 8,50 \\
\hline Jedinstvo, Sevojno & 6,78 & 12,2 & $-5,42$ \\
\hline Palisad, Zlatibor & 2,29 & 12,2 & $-9,91$ \\
\hline PKB Korporacija, Bgd & 1,39 & 12,2 & $-10,81$ \\
\hline
\end{tabular}

Izvor: Prikaz autora

Tabela 6. Realne SGR odabranih preduzeća u Srbiji u 2013. godini

\begin{tabular}{lccc}
\hline \multicolumn{1}{c}{ Preduzeće } & g - održiva stopa rasta & stopa inflacije & realna održiva stopa rasta \\
\hline Bambi, Požarevac & 26,95 & 2,2 & 24,75 \\
\hline Jedinstvo, Sevojno & 7,17 & 2,2 & 4,97 \\
\hline Palisad, Zlatibor & 0,19 & 2,2 & $-2,01$ \\
\hline PKB Korporacija, Bgd & 9,12 & 2,2 & 6,92 \\
\hline
\end{tabular}

Izvor: Prikaz autora

Tabela 7. Realne SGR odabranih preduzeća u Republici Srpskoj u 2012. godini

\begin{tabular}{lccc}
\hline \multicolumn{1}{c}{ Preduzeće } & g-održiva stopa rasta & stopa inflacije & realna održiva stopa rasta \\
\hline Boksit, Milići & 2,59 & 2,1 & 0,49 \\
\hline Krajina GP B. Luka & 1,68 & 2,1 & $-0,42$ \\
\hline Banja Vrućica, Teslić & 3,12 & 2,1 & 1,02 \\
\hline Industrijske plantaže B. Luka & 0,03 & 2,1 & $-2,07$ \\
\hline
\end{tabular}

Izvor: Prikaz autora

Tabela 8. Realne SGR odabranih preduzeća u Republici Srpskoj u 2013. godini

\begin{tabular}{lccc}
\hline \multicolumn{1}{c}{ Preduzeće } & $\mathrm{g}$ - održiva stopa rasta & stopa inflacije & realna održiva stopa rasta \\
\hline Boksit, Milići & 6,13 & 0,0 & 6,13 \\
\hline Krajina GP B. Luka & 3,47 & 0,0 & 3,47 \\
\hline Banja Vrućica, Teslić & 1,46 & 0,0 & 1,46 \\
\hline Industrijske plantaže B.Luka & 0,03 & 0,0 & 0,03 \\
\hline
\end{tabular}

Izvor: Prikaz autora

Sasvim drugačija situacija je zabeležena kod analiziranih korporacija iz Republike Srpske (tabele 7 i 8) kod kojih je, iako sa znatno nižim nominalnim održivim stopama rasta u 2012. godini, ipak dve korporacije beležilo pozitivne realne održive stope rasta, a dve korporacije negativne realne održive stope rasta, što je bolji rezultat nego što su pokazale korporacije iz Srbije u istoj godini i to prvenstveno zahvaljujući znatno nižoj stopi inflacije u Republici Srpskoj od 2,1\% vs. $12,2 \%$ u Srbiji u istoj godini. U 2013. godini, sve analizirane korporacije iz Republike Srpske su zahvaljujući nultoj stopi inflacije u toj godini, zabeležile pozitivne realne održive stope rasta. Otuda se može konstatovati da su polovina posmatranih korporacija u Republici Srpskoj u 2012. godini i sve posmatrane korporacije u 2013. godini posedovale realni potencijal za rast, što je bolji rezultat nego kod korporacija iz Srbije. Sa druge strane, pojedinačno gledano, one korporacije iz Srbije koje su uspele da ostvare pozitivne realne održive stope rasta, ostvaruju ih na višem nivou nego što ih ostvaruju korporacije iz Republike Srpske.

\section{REZIME}

Na osnovu sprovedenog istraživanja postavljene hiporeze su jednim delom potvrđene, a drugim delom opovrgnute. $\mathrm{H} 1$ je opovrgnuta jer je pokazano da postoji značajna razlika između održive stope rasta analiziranih korporacija iz Srbije, sa jedne strane, i analiziranih korporacija iz Republike Srpske sa druge strane i to u korist korporacija iz Srbije. H2 je potvrđena u smislu da ne postoji značajna razlika između održive stope rasta posmatranih korporacija u celini u 2013. godini u odnosu na 2012. godinu, iako manja razlika postoji kod jednog dela pojedinačnih korporacija. H3 je opovrgnuta jer je utvrđeno da postoji značajna razlika između nominalne i realne održive stope rasta korporacija u 2012. godini u Srbiji zbog visoke stope inflacije u toj godini, a da ta razlika postoji i kod korporacija iz Republike Srpske, ali u manjoj meri zbog niske stope inflacije u posmatranoj godini u Republici Srpskoj. H4 je delimično potvrđena po pitanju razlike između nominalne i realne održive stope rasta korporacija u Srbiji u 2013. godini, jer su te razlike realtivno male zbog niske stope inflacije u Srbiji u toj godini, a apsolutno je potvrđena po pitanju razlike između nominalne i realne održive stope rasta korporacija u Republici Srpskoj u 2013. godini, jer te razlike nije bilo zbog nulte stope inflacije u Republici Srpskoj u toj godini.

Obzirom na sličan geografski položaj, slične socijalne i prirodne karakteristike i klimatske uslove, posmatrane korporacije u Srbiji i Republici Srpskoj imaju značajan razvojni potencijal i predispozicije da postanu važan segment razvoja ekonomije posmatranih zemalja. Zbog toga bi se moglo 
očekivati da analizirane korporacije imaju sličnu održivu stopa rasta u obe zemlje. Međutim, poređenjem poslovanja korporacija iz različitih privrednih grana u dve uzastopne godine (2012. i 2013.), pokazalo se da su korporacije iz Srbije beležile znatno više nominalne održive stope rasta nego korporacije iz Republike Srpske i to prvenstveno zbog viših stopa profitabilnosti - ROE, odnosno viših profitnih marži. Međutim, kada se pored mikroekonomskih faktora, u obzir uzmu i makroekonomski faktori koji uzrokuju makroekonomsku stabilnost koja se iskazuje kroz cenovnu stabilnost, odnosno nisku stopu inflacije, onda se dolazi do podataka o visini realne održive stope rasta, pri čemu veći procenat korporacija iz Republike Srpske beleži pozitivne rezultate nego korporacije iz Srbije i to prvenstveno zahvaljujući većoj makroekonomskoj stabilnosti, odnosno nižoj, čak i nultoj stopi inflacije. Otuda se vidi veliki značaj obezbeđivanja makroekonomske stabilnosti za potencijalni, samostalni, realni razvoj korporacija u pojedinim zemljama. Pojedinačnim upoređivanjem korporacija iz Srbije i Republike Srpske, može se zapaziti i da u slučajevima kada korporacije iz Srbije ostvare pozitivnu realnu održivu stopu rasta i pored makroekonomskih opterećenja tj. više stope inflacije, onda su ove stope na višem nivou nego što su realne održive stope rasta korporacija iz Republike Srpske, a to je posledica prvenstveno jačih mikroekonomskih pokazatelja korporacija iz Srbije koji utiču na visinu profitnih marži i profitnih stopa.

Sklonost isplaćivanju dividendi je slična kod posmatranih korporacija u obe zemlje u posmatranom periodu, pa nije bilo velikih razlika u retention rate koje bi odlučujuće uticale na krajnji rezultat visine održivih stopa rasta, što olakšava uporedivost dobijenih rezultata.

Analiza je sprovedena na ograničenom broju profitabilnih korporacija, pa se i ograničenje istraživanja poklapa sa sveobuhvatnošću analize na najširoj bazi korporativnih preduzeća u obe zemlje.

Značaj poznavanja održivih stopa rasta je veliki za korporativni finansijski menadžment. Niska održiva stopa rasta korporacija bilo u Srbiji ili Republici Srpskoj označava njihov nizak potencijal za samostalni rast bez dodatnih zaduživanja, a ubrzani rast ovih korporacija preko održive stope rasta uz dodatna ili čak prekomerna zaduživanja, može ovim korporacijama stvoriti likvidnosne probleme, a u težim slučajevima, čak ih uvesti i u bankrotstvo. Ista opasnost preti ovim korporacijama ukoliko odustanu od rasta i ne iskoriste ni nivo održive stope rasta, jer ih to vodi u stagnaciju, gubitak postojeće tržišne pozicije, a u krajnjem slučaju takođe ih može voditi u bankrotstvo.
Za dalji ubrzaniji razvoj korporacija u Srbiji i Republici Srpskoj, interno je potrebno stalno unapređivati efikasnost i profitabilnost ovih preduzeća na mikro nivou, dok je eksterno na makro nivou potreban napor matičnih država da obezbede stabilne, zdrave uslove poslovanja, a posebno da održe cenovnu stabilnost tj. nisku stopu inflacije, što je Republici Srpskoj u uslovima funkcionisanja Valutnog odbora lakše postići, a takođe je potrebno i da se osmisle adekvatne stimulativne mere za podsticanje rasta i razvoja korporacija iz prioritetnih grana delatnosti za koje se ove zemlje opredele, čime bi se obezbedio pristup jeftinijim i namenskim, specijalizovanim izvorima finansiranja i zaduživanja.

Sprovedeno istraživanje može da posluži kao osnova za dalja istraživanja na ovu temu i različita komparativna sagledavanja realnih potencijala rasta različitih grana delatnosti unutar privrede analiziranih zemalja.

\section{LITERATURA}

Braley, R., \& Myers, S. (2003). Principles of Corporate Finance $\left(7^{\text {th }}\right.$ ed.). New York: McGraw-Hill.

Chen, H.Y., Gupta, M.C., Lee, A.C., \& Lee, C.F. (2013). Sustainable growth rate, optimal growth rate, and optimal payout ratio: A joint optimization approach, Journal of Banking \& Finance, 37(4), 1205-1222.

Clouse, M., \& McFaddin, S. (1994). Sustainable growth in the US gas utility industry, Resources Policy, 20(2), 117-123.

Higgins, R.C. (1977). How Much Growth Can a Firm Afford? Financial Management, 6(3), 7-16.

Higgins, R.C. (1981). Sustainable Growth Under Inflation. Financial Management, 10(4), 36-40.

Jović, Z., Vićentijević, K., Petrović, Z. (2015). Održiva stopa rasta hotelskih i ugostiteljskih preduzeća u Srbiji. U: SITCON 2015, 25. septembar 2015 (122-126). Beograd: Univerzitet Singidunum.

Ministarstvo finansija (2014). Osnovni indikatori makroekonomskih kretanja, htpp://www.mfin.gov.rs/

Republički zavod za statistiku Republike Srpske (2015). Statistički godišnjaci, http://www.rzs.rs.ba/

Stowe, J. (2000). Analysis of Equity Investments. Boston: AIMR. Pearson Custom Publishin.

Zvanična internet stranica Banjalučke berze a.d., https://www. blberza.com, datum posete 29.10.2015.

Zvanična internet stranica Beogradske berze a.d., http://www. belex.rs/, datum posete 26.10.2015.

\section{THE ROLE OF SUSTAINABLE GROWTH RATES IN CORPORATE FINANCIAL MANAGEMENT}

\begin{abstract}
:
All profitable corporations can get into financial difficulties and even bankruptcy if they grow slower or faster than recommended. The assessment of too slow or too rapid growth of corporate enterprises is achieved through comparison with their sustainable growth rates. The mere sustainable growth rate is the maximum growth rate that a corporation can achieve without additional borrowings. The aim of this study is to determine the sustainable growth rate of certain corporate enterprises in Serbia and the Republic of Srpska in 2012 and 2013., as well as to determine whether there is any difference between these corporations in the Republic of Serbia and the Republic of Srpska. In addition, the study seeks to establish a realistic and sustainable growth rate of the analysed enterprises in these two countries, taking into account the current inflation rate for the observed years, as well as to clarify differences between nominal and real sustainable growth rates. The identified real sustainable growth rates of the analysed enterprises in the Republic of Serbia and the Republic of Srpska can serve as guidelines in drawing conclusions about the developing potential of these corporations and provide support to finding the appropriate internal and external solutions needed for further growth potential of such corporations.
\end{abstract}

Key words:

sustainable growth rate, corporations, financial management, dividend policy. 